\title{
Migration of Intraocular Silicone Oil to CNS: The Role of Elevated Intraocular Pressure and Congenital Optic Nerve Abnormalities
}

\author{
A. Grzybowski · F. J. Ascaso
}

Published online: 7 September 2015

(C) The Author(s) 2015. This article is published with open access at Springerlink.com

\section{Dear Editor,}

We have read with interest the article "Intracranial Migration of Intravitreal Silicone Oil: A Case Report" published by Kim et al. [1]. We would like to congratulate them for the phantom study of silicon oil ( $\mathrm{SiO}$ ) and perfluorocarbon liquid (PFCL). We believe, however, that some discussion of this article is needed. In fact, we must clarify that, although both types of intraocular tamponade are used today, $\mathrm{SiO}$ is a long-term intraocular tamponade, whereas PFCL is only used as intraoperative tool and must be extracted at the end of surgery. We agree with the authors that the increased intraocular pressure of the patient may have caused intra-

This article should be linked together with doi:10.1007/s00062015-0379-x.

A. Grzybowski $(\square)$

Department of Ophthalmology, Poznan City Hospital,

3 Szwajcarska St,

361-285 Poznań, Poland

e-mail: ae.grzybowski@gmail.com

\section{A. Grzybowski}

Chair of Ophthalmology, University of Warmia and Mazury,

Olsztyn, Poland

\section{F. J. Ascaso}

Medical and Surgical Retina Unit, Department of

Ophthalmology, Hospital Clínico Universitario Lozano Blesa,

Zaragoza, Spain

\section{F. J. Ascaso}

School of Medicine, University of Zaragoza,

Zaragoza, Spain

F. J. Ascaso

Instituto de Investigación Sanitaria de Aragón (IIS Aragón),

Zaragoza, Spain cranial migration of $\mathrm{SiO}$ [2]. However, they provide no information about either the evolution during the 9 months of follow-up or the presence of congenital optic nerve disc anomalies. Finally, we also believe that the article should include the characteristics of the $\mathrm{SiO}$ employed. These clinical data regarding the presence of any of these predisposing factors in the patient might have played a crucial role in physical silicone migration.

\section{Conflict of Interest The authors have no conflict of interest.}

Open Access This article is distributed under the terms of the Creative Commons Attribution Noncommercial License which permits any noncommercial use, distribution, and reproduction in any medium, provided the original author(s) and source are credited.

\section{References}

1. Kim H, Hong HS, Park J, Lee AL. Intracranial migration of intravitreal silicone oil: a case report. Clin Neuroradiol. 2015 Feb 27. [Epub ahead of print]

2. Grzybowski A, Pieczynski J, Ascaso FJ. Neuronal complications of intravitreal silicone oil. an updated review. Acta Ophthalmol. 2014;92:201-4. 